\title{
A case of congenital triple valve disease
}

\author{
J-P. VAN BESOUW \\ B.Sc., M.B., B.S. \\ G. ORR \\ M.B., M.R.C.P.
}

\author{
N. A. SHEPHERD \\ M.B., B.S. \\ S. H. D. JACKSON \\ M.B., M.R.C.P.
}

St Bartholomew's Hospital, London EC1

\begin{abstract}
Summary
We report a case of congenital triple valve stenosis with dominant pulmonary valve disease, sparing the aortic valve, presenting at the age of 51 years with progressive shortness of breath and central cyanosis. At post mortem, no intracardiac right to left communication could be demonstrated.
\end{abstract}

KEY WORDS: congenital heart disease.

\section{Introduction}

The occurrence of combined valve disease is a rare but well-recognized form of congenital heart disease, and in most cases is thought to be associated with a chromosomal abnormality and almost always with intrauterine death or death within the first few months of life (Bharti and Lev, 1973).

\section{Case report}

A 51-year-old woman attended the Casualty Department with a 3-day history of increasing shortness of breath, ankle swelling and cyanosis. She had been feeling generally unwell and had been forced to give up work 12 months previously because of decreasing exercise tolerance. There was no history of chest pain or collapse. She had been well all her life until the time of her present illness. There was no history of rheumatic fever. She was not taking any medication and she had never been pregnant.

On examination, she appeared centrally cyanosed, tachypnoeic, had a heart rate of $180 / \mathrm{min}$ and an unrecordable blood pressure. There was a prominent parasternal heave and evidence of gross right-sided heart failure with bilateral pitting oedema to the thigh, a palpable liver and elevated jugular venous pressure $15 \mathrm{~cm}$ above the sternal angle. No cardiac murmurs were heard. The chest was clear. The electrocardiogram (ECG) showed right axis deviation with right ventricular hypertrophy, with a supraventricular tachycardia. The chest X-ray showed oligaemic lung fields and a normal sized heart. The cardiothoracic ratio was $14 / 28 \cdot 5$. Plasma sodium was $128 \mathrm{mmol} /$ litre, bicarbonate $17 \mathrm{mmol} /$ litre and urea $27.4 \mathrm{mmol} /$ litre. Potassium analysis was unsatisfactory due to haemolysis. Arterial blood gases were $\mathrm{PaO}_{2} 1.9 \mathrm{kPa}, \mathrm{PaCO}_{2} 7.75 \mathrm{kPa}$ and hydrogen ion concentration $65 \mathrm{nmol} / \mathrm{litre}$.

The supraventricular tachycardia was treated with $5 \mathrm{mg}$ of intravenous verapamil, resulting in a slowing of the ventricular rate to $80 / \mathrm{min}$ with clinical improvement in output. At this rate, the ECG also showed right bundle branch block.

Shortly following this, she had a respiratory arrest, was intubated and given $100 \%$ oxygen $\left(\mathrm{O}_{2}\right)$. A doxapram infusion was set up but she then had a cardiac arrest.

At post mortem, the lungs and pulmonary arteries were macroscopically normal, but no histology is available. The heart weighed $560 \mathrm{~g}$ (normal weight $300 \pm 40 \mathrm{~g}$ ) and all the coronary arteries were widely patent with minimal atheroma. The right atrium was dilated with marked myocardial hypertrophy. The left atrium was moderately dilated but also showed myocardial hypertrophy. There was no evidence, despite vigorous probing, of a communication between the two atria or the two ventricles. There was gross right ventricular hypertrophy, the wall being 2 $\mathrm{cm}$ thick (upper limit of normal $0.4 \mathrm{~cm}$ ). There was also mild left ventricular hypertrophy but no evidence of myocardial infarction.

The pulmonary valve showed the typical cupola of congenital stenosis, the maximum lumen diameter being reduced to $0.4 \mathrm{~cm}$, reducing the area of the valve lumen to $3.5 \%$ of its maximal area. There was no calcification and no vegetations.

The aortic valve appeared normal. The tricuspid and mitral valves both showed deformity with 
stenosis. The macroscopic appearance of both was of congenital valve disease. Histology of the myocardium, endocardium and heart valves showed no evidence of rheumatic heart disease.

A diagnosis was made of congenital triple valve disease with a tight pulmonary stenosis, together with mitral and tricuspid stenosis and secondary right ventricular, right atrial and left atrial hypertrophy.

\section{Discussion}

Apart from the hitherto undescribed combination of valve lesions, the age of presentation makes this case very unusual. Although isolated mild to moderate pulmonary stenosis may remain asymptomatic until middle age or later (St John Sutton and St John Sutton, 1979), a stenosis reducing the valve lumen by 97\% would be expected to produce a right ventricular pressure greater than $80 \mathrm{mmHg}$ if it was an isolated lesion (Nugent, Freedom and Nora, 1977). The presence of tricuspid stenosis would have reduced the right ventricular pressure and therefore reduced the haemodynamic disturbance. Similarly the haemodynamic effect of the mitral stenosis would have been minimized by reduced pulmonary blood flow.

Clinically, the patient was centrally cyanosed, a finding supported by the arterial blood gas analysis. The usual explanation for the development of cent cyanosis in an adult with pulmonary stenosis is the development of a right to left shunt caused by the opening up of the foramen ovale. As a result of the post mortem studies, we are confident that this was not the explanation in this case and that consequen any shunt must have been within the pulmonapy circulation although we are unable to explain why this should have occurred.

It is possible that the blood gas analysis was performed on venous blood but we feel that is unlikely in view of the failure to correct the cyanosis during cardiopulmonary resuscitation using $100 \% \Phi_{2}$.

\section{Acknowledgment}

We thank Professor P. Turner for allowing us to present this caise

\section{References}

BharTi, L. \& LEV, M. (1973) Congenital polyvalvular dise\&e. Circulation, 47, 575.

NUGENT, E.W., FrEedoM, R.M. \& NORA, J.J. (1977) Clinical course in pulmonary stenosis. Report from the joint study on the natuval history of congenital heart defects. Circulation, 56 (Suppl. 1), ST John SuTTON, M.G. \& ST John SuTton, M.B. (1979) Congenimal valve disease. British Journal of Hospital Medicine, 22, 226.

(Accepted 11 January 1983) 